\title{
A PRODUÇÃO DE AUTORIA FEMININA ATRAVÉS DA EDITORA MULHERES: ENTREVISTA COM ZAHIDÉ MUZART
}

\author{
Jailma dos Santos Pedreira Moreira
}

\begin{abstract}
RESUMO: Trata-se de uma entrevista com Zahidé Muzart, uma das criadoras da Editora Mulheres. Nesta buscamos saber como e por que a Editora Mulheres foi criada, quais suas dificuldades, estratégias e conquistas, assim como, a partir da organização da editora, Muzart avalia sua inserção no mercado editorial, a participação da produção de autoria feminina na cadeia produtiva e o apoio de políticas públicas e de instituições nesta dinâmica. Traços da trajetória da Editora Mulheres são revelados, tornando visível a importância do trabalho que desenvolve na rasura de uma tradição literária/cultural/mercadológica.
\end{abstract}

PALAVRAS-CHAVE: Editora Mulheres. Produção de autoria feminina. Cadeia produtiva.

ABSTRACT: This is an interview with Zahide Muzart, one of the creators of Women Publisher. In this we seek to know how and why the Publisher Women was created, what their difficulties, strategies and achievements, as well as from the organization's publisher, Muzart evaluates its insertion in the publishing market, participation in the production of female authorship in the production chain and support of public policies and institutions in this dynamic. Traces the trajectory of Women Publisher are revealed, making visible the importance of the work that develops the erasure of a literary tradition / cultural / marketing.

KEYWORDS: Women Publisher. Production of female authorship. Chain.

Como já dissemos em resumo, trata-se de uma entrevista com Zahidé Lupinacci Muzart, uma das criadoras da Editora Mulheres. Muzart possui graduação em Letras Neolatinas pela Pontifícia Universidade Católica do Rio Grande do Sul (1961), Graduação em Música pela Escola de Artes da Universidade Federal do Rio Grande do Sul, doutorado em Letras pela Faculté des Lettres et Sciences Humaines, Université de Toulouse-Le Mirail (1970), pósdoutorado na Ecole des Hautes Etudes em Sciences Sociales, Paris (1983-1984). Tem experiência na área de Letras, com ênfase em Literatura Brasileira (História das escritoras no século XIX, Literatura e Mulher, feminismo e literatura etc.). Participa da coordenação do Instituto de Estudos de Gênero - IEG/UFSC, de duas editorias da Revista Estudos Feministas e é a responsável, atualmente, pela Editora Mulheres. Nesta entrevista buscamos saber, através de algumas perguntas feitas por correio eletrônico, em junho de 2012, como e por que a Editora Mulheres foi criada, quais suas dificuldades, estratégias e conquistas nestes 16 anos 
de existência, assim como, a partir da organização da editora, Muzart avalia sua inserção no mercado editorial, a participação da produção de autoria feminina na cadeia produtiva e o apoio de políticas públicas e instituições nesta dinâmica. Traços da trajetória da Editora Mulheres são revelados, tornando visível o lugar de sua produção, suas demandas, táticas e conquistas apontando para a importância do trabalho que desenvolve na rasura de uma tradição literária/cultural e mercadológica, marcada por um capital patriarcal, que desconsiderou e, em certa medida ainda desconsidera, a produção e edição de autoria feminina. A entrevista ainda nos leva a refletir sobre o trabalho cooperativo realizado pela Editora e o quanto este ciclo de edição poderia fortalecer, com apoio de diversas políticas públicas e instituições, e já ampliando o pensamento para tantas outras (possíveis) experiências femininas de produção, uma cadeia produtiva com seus eixos de produção e distribuição/circulação. Nesse sentido, vale a pena conferir a entrevista logo abaixo.

Jailma Pedreira Moreira: Como e por que foi criada a editora Mulheres?

Zahidé Muzart: A ideia da editora, apesar de gestada há muitos anos pela pesquisa com textos de mulheres, surgiu meio de repente. Em 1995, éramos três professoras de literatura da UFSC e aposentadas. E o bom de ser aposentada é que se pode fazer o que se quiser. Como estávamos pesquisando sobre as escritoras brasileiras do século XIX, e a maior dificuldade da pesquisa era o encontro com os livros, sugeri às duas amigas de criarmos uma editora que tivesse como principal preocupação a reedição desses velhos textos.

No início da pesquisa, era voz corrente de que aquelas mulheres do século XIX nada tinham escrito, e, por conseguinte, menos ainda publicado. Logo ficou evidente, porém, que, na verdade, não só escreveram e publicaram uma grande quantidade de textos, mas, bem mais que isso, que esses textos constituíam um legado de boa qualidade literária e de valor histórico inquestionável. Era, pois, fundamental republicá-los hoje. A pesquisa se inscreve no trabalho de arqueologia literária próprio da crítica feminista e igualmente à tendência de uma crítica feminista interessada no estabelecimento de uma tradição literária escrita por mulheres: uma literatura própria. E, ao lado dessa linha mestra de resgate, a editora se propunha a editar ensaios sobre gênero. Tratava-se de um projeto muito bem definido e a editora já nasceu diretamente vinculada a uma linha de investigação estabelecida, Literatura e Mulher, 
decorrente de nossa filiação a um grupo de pesquisa da ANPOLL (Associação Nacional de Pós-Graduação e Pesquisa em Letras e Linguística): A Mulher na Literatura.

JPM: Nestes 16 anos de existência, segundo a sua perspectiva, quais foram ou são as maiores dificuldades enfrentadas pela Editora e quais suas grandes conquistas?

ZM: No início, a maior dificuldade era a falta de respeito com o nome Mulheres. Era necessário repetir o nome, ao telefone, e havia sempre uma espécie de riso escondido que adivinhávamos!! Com os anos, com o feminismo crescente, isso já não mais ocorre.

As pequenas editoras enfrentam sempre inúmeros problemas e um deles, talvez o maior, é a questão da distribuição dos livros para as livrarias. Atualmente, não tenho distribuidores. Fui obrigada a cancelar contrato com os que já tive porque não havia meios de conseguir receber o que me deviam nos prazos, ou mesmo fora dos prazos, e quando devolviam os livros não era mais possível vendê-los (exemplo, alguns distribuidores do Rio e São Paulo) tão deteriorados voltavam. Os descontos dos distribuidores são muito altos, 55\% é o mínimo. Alguns não pagam o frete. As grandes livrarias, que atualmente dominam o mercado, exigem no mínimo $55 \%$ a $60 \%$ de desconto e não pagam o frete.

$\mathrm{Eu}$, realmente, enfrentei dificuldades com distribuidores e livreiros. Por isso, desisti de tê-los, mas reconheço que a distribuição é uma dificuldade enorme e comum a editores na província, ou seja, fora do eixo...

Mas apesar desses percalços, podemos dizer que a editora, na sua linha de resgate de textos de escritoras do século XIX, de viajantes estrangeiras como a Baronesa de Langsdorff, e os estudos de gênero obteve muita credibilidade e respeito. Também foi importante o fato de termos publicado livros traduzidos de importantes historiadoras como Joan Scott, ${ }^{1}$ June Hahner, ${ }^{2}$ Jean Franco ${ }^{3}$ e Nara Araújo. ${ }^{4}$

JPM: A partir da organização e funcionamento da Editora Mulheres, como avalia a inserção da produção feminina no mercado editorial? Quais as ciladas e estratégias nesta dinâmica?

\footnotetext{
${ }^{1}$ SCOTT, Joan W. A cidadã paradoxal: as feministas francesas e os direitos do homem. Tradução de: Élvio Antônio Funk. 2002.

${ }^{2}$ HAHNER, June E. Emancipação do sexo feminino: a luta pelos direitos da mulher no Brasil. Tradução de: Eliane Lisboa. 2003.

${ }^{3}$ JEAN FRANCO. Marcar diferenças, cruzar fronteiras. Tradução de Alai Garcia Diniz. 2005. 364 p.

${ }^{4}$ ARAÚJO, Nara. O tempo e o rastro: da viagem e sua imagem. Tradução de: Eliane Tejera Lisboa. 2003.
} 
ZM: A Editora Mulheres embora seja uma editora de fundo de quintal, sem funcionários, sem bons distribuidores, ficou muito conhecida. Por quê?

Em primeiro lugar, pelo ineditismo de suas edições do século XIX. Vou dar apenas um exemplo, pois não há possibilidade de comentar a origem das várias edições: o resgate de uma escritora como Júlia Lopes de Almeida (1862-1934) que começou a partir de 1996, ou seja, há 16 anos. Raríssimos críticos literários falavam dela e até os anos 60, somente foi contemplada por Lúcia Miguel-Pereira em Prosa de ficção: de 1870 a 1920, publicado em $1957 . .^{5}$ A escritora não aparecia nas Histórias da Literatura, a não ser em rodapé, ou nas listas de autores menores. Pois, a partir das publicações de alguns romances, ela foi se tornando mais e mais conhecida, aparecendo em congressos, palestras e em muitas comunicações não só no Brasil como nos Estados Unidos. O primeiro livro que editamos foi A Silveirinha.

Da mesma autora, depois de A Silveirinha, publicamos A Viúva Simões, A falência, Memórias de Marta e A família Medeiros. Todas as edições seguem o mesmo esquema: um aprofundado estudo de especialista, uma cronologia da vida e obra, a bibliografia da autora e sobre a autora. Nossas edições são um trabalho conjunto com a organizadora. O ressurgimento de Júlia Lopes de Almeida originou teses e dissertações, artigos e ensaios não só na área de Letras, mas também na área de História. No Banco de Teses da Capes, encontrei mais de dez trabalhos sobre Júlia Lopes de Almeida entre dissertações e teses.

Atualmente, pois, a escritora está sendo reavaliada pelos estudos acadêmicos. Todo esse movimento de resgate, de renascimento de mulheres escritoras, no Brasil, é consequência dos estudos na linha de pesquisa Mulher e Literatura que é herdeira direta dos estudos feministas que se desenvolveram, sobretudo, nos Estados Unidos, muito mais do que em qualquer outro país; e à tendência de uma crítica feminista interessada no estabelecimento de uma tradição literária escrita por mulheres. E nesse ponto, a editora Mulheres teve, no Brasil, um papel fundamental com suas reedições.

A Editora nos tem proporcionado muitas alegrias no contato com várias pessoas. Um dos encontros mais simpáticos que tivemos foi a visita do neto de Júlia Lopes de Almeida, em 2002, Dr. Cláudio Lopes de Almeida. Esteve, acompanhado de sua esposa e neta, em minha casa e, desde então, tem sido um incentivador de todo o nosso trabalho pelo ressurgimento da

${ }^{5}$ PEREIRA, Lúcia Miguel. Prosa de ficção: de 1870 a 1920. 2. ed. Rio de Janeiro: José Olympio, 1957. p. $255-$ 71. 
avó. E ele mesmo tem feito um grande trabalho de conservação do acervo de D. Júlia, possibilitando novos estudos. Quando do congresso da BRASA, no Rio em 2003, organizamos uma mesa-redonda sobre a obra de Júlia Lopes de Almeida, seu neto compareceu e deu-nos um belo depoimento. Foi, realmente, uma sessão memorável!

JPM: No que diz respeito à produção feminina no Brasil, como a observa no percurso da cadeia produtiva, ou seja, desde a produção até a distribuição/circulação mais ampla e democrática. É possível falar em uma cadeia de produção feminina forte? Caso não, como potencializá-la?

ZM: É-me difícil discutir esse ponto talvez por me faltarem mais informações. Vou falar de meu ponto de vista em relação à Editora Mulheres. Parece-me que essa cadeia de produção feminina forte existiu enquanto concepção da Editora, apoio, reunião de pesquisadoras e ensaístas. Até a edição podemos dizer que fecha-se o círculo, já que muitas das participantes deste trabalho fazem parte dos estudos de gênero em várias universidades . E os estudos de gênero estão de certa forma organizados e legitimados nas universidades com alguns projetos incentivados pela Secretaria de Política para Mulheres. Quanto ao campo editorial e mercadológico posso dizer que não há uma distribuição e uma circulação ampla e democrática. Basta procurar a produção feminina em livrarias, em sites especializados. Há sempre uma dificuldade desses livros terem divulgação e, consequente, circulação. Ou viceversa. Nesse sentido é rompida a cadeia produtiva.

JPM: Qual o papel das instituições e das políticas públicas no apoio a produção e distribuição/circulação da produção literária de autoria feminina? O que há neste cenário que mereça destaque?

ZM: Acho que há um apoio muito grande da parte da Secretaria das Mulheres aos grupos de estudos de gênero. Fizemos praticamente todos os livros oriundos do evento Fazendo Gênero financiados pela Secretaria. Quanto a outras instituições, desconheço. Uma coisa que nos tem apoiado muito é o fato de contarmos com as co-edições com editoras universitárias como a EDUNISC, da Universidade de Santa Cruz do Sul, da Editora da PUC de Minas Gerais e da Universidade de Goiás.

JPM: Por fim, qual a importância de refletirmos sobre produção feminina? Quais os seus significados/contribuições e quais projetos e perspectivas a Editora Mulheres tem em meta atualmente? 
ZM: Como disse Antonina Rodrigo, em 1996, Mira, Montserrat, si no hablamos nosotras de nosotras, quién lo va a hacer? Atualmente, continuo com o projeto dominante de resgate da produção das escritoras do século XIX pois se não as editamos nós, "quién lo va a hacer?". Vamos publicar neste ano o romance de Juana Paula Manso ( Mistérios del Plata), a fundadora do primeiro periódico dirigido somente por mulheres e cujo objetivo era um diálogo com as mulheres, o Jornal das Senhoras, publicado em 1852. Além deste, temos mais dois livros de Júlia Lopes de Almeida (Cruel amor. Rio de Janeiro: Francisco Alves, 1911 e Ânsia eterna. Rio de Janeiro: H. Garnier, 1903). E ainda dois romances de Chrysanthème, uma excelente escritora de quem até hoje nada publicamos. Na Série Feministas temos três livros já preparados e esperando tempos mais amenos para publicá-los.

JPM: Muito obrigada, Zahidé Muzart, pela solicitude e disponibilidade em nos atender.

RECEBIDO EM: 07 de maio de 2012

APROVADO EM: 14 de junho de 2012 